\title{
Mulheres que denunciam violência de gênero em uma Unidade de Polícia Pacificadora
}

Women who report gender violence at a Peacemaking Police Unit

Mujeres denunciantes de violencia de género en una Unidad de Policía Pacificadora

Maria Aparecida Vasconcelos Moura', Leônidas de Albuquerque Netto², Francièle Marabotti Costa Leite, Francinne Raposo de Souza Lima ${ }^{4}$, Selma Villas Boas Teixeira ${ }^{5}$

\footnotetext{
1 Enfermeira, Doutora em Enfermagem. Professora Associada da Escola de Enfermagem Anna Nery da Universidade Federal do Rio de Janeiro (EEAN/UFRJ). Rio de Janeiro, RJ, Brasil. E-mail: maparecidavas@yahoo.com.br.

${ }^{2}$ Enfermeiro. Discente do Programa de Pós-Graduação da EEAN/UFRJ, nível Mestrado. Rio de Janeiro, RJ, Brasil. E-mail: leonidasalbuquerque@bol.com.br.

${ }^{3}$ Enfermeira, Mestre em Saúde Coletiva. Professora Assistente do Departamento de Enfermagem da Universidade Federal do Espírito Santo. Vitoria, ES, Brasil. E-mail: emaildafran@ig.com.br.

${ }^{4}$ Acadêmico do curso de Graduação em Enfermagem da EEAN/UFRJ. Rio de Janeiro, RJ, Brasil. E-mail: frslima@hotmail.com.

${ }^{5}$ Enfermeira, Mestre em Enfermagem. Discente do Programa de Pós-Graduação da EEAN/UFRJ, nível Doutorado. Rio de Janeiro, RJ, Brasil. E-mail: selma.villasboas@globo.com.
}

\section{RESUMO}

Estudo cujo objetivo foi analisar a violência de gênero contra mulheres a partir dos registros de uma Unidade de Polícia Pacificadora do Rio de Janeiro/Brasil. Estudo quantitativo, retrospectivo, transversal, com amostra de 89 registros de mulheres que denunciaram as agressões. As informações foram analisadas por meio do programa SPSS 17.0. Prevaleceram os tipos de violência: 66,3\% física, 23,6\% psicológica, 7,9\% física e psicológica, e 2,2\% sexual. A maioria das mulheres (50,6\%) não registrou a violência em Boletim de Ocorrência. Verificou-se que $69,7 \%$ dos casos ocorreram em residência, sendo os agressores conhecidos (70,8\%). Entre aquelas que não registraram a denúncia, na maioria dos casos, os agressores foram os parceiros íntimos. A mulher violentada necessita de atenção especial dos serviços de segurança. Este estudo abre espaço frente à realidade de uma comunidade pacificada, aliada à relação de confiança, apoio e inserção social das mulheres violentadas junto à Unidade de Polícia Pacificadora.

Descritores: Enfermagem; Saúde da Mulher; Violência contra a Mulher; Mulheres Maltratadas; Gênero e Saúde.

\section{ABSTRACT}

The objective was to analyze gender violence against women based on the record of a Peacemaker Police Unit of Rio de Janeiro/Brazil. This quantitative, retrospective, cross-sectional study was performed with a sample of 89 records filed by women victims. The information was analyzed using SPSS 17.0. The following types of violence prevailed: $66.3 \%$ physical, $23.6 \%$ psychological, $7.9 \%$ physical and psychological, and 2.2\% sexual. Most women (50.6\%) did not file a police report. It was found that $69.7 \%$ of cases occurred at home, with the assailant being someone the woman knew (70.8\%). Among the women who did not file a complaint, in most cases, the assailants were their intimate partner. The assaulted woman requires special attention from safety services. This study opens a discussion regarding the true situation of a pacified community allied to the relationship of rust, support and social inclusion of assaulted women with the Peacemaker Police Unit.

Descriptors: Nursing; Women's Health; Violence Against Women; Battered Women; Gender and Health.

\section{RESUMEN}

Se objetivó analizar la violencia de género contra mujeres a partir de registros de una Unidad de Policía Pacificadora de Rio de Janeiro/Brasil. Estudio cuantitativo, retrospectivo, transversal, con muestra de 89 registros de mujeres que denunciaron agresiones. Informaciones analizadas con SPSS 17.0. Prevalecieron los tipos de violencia: $66,3 \%$ física, 23,6\% psicológica, 7,9\% física y psicológica, 2,2\% sexual. La mayoría de las mujeres (50,6\%) no realizó Exposición Policial. Se verificó que 69,7\% de los casos ocurrieron en domicilio, siendo los agresores conocidos (70,8\%). Entre aquellas que no registraron la denuncia, en la mayoría de casos los agresores fueron las parejas íntimas. La mujer violentada necesita atención especial de los servicios de seguridad. Este estudio abre espacio frente a la realidad de una comunidad pacificada aliada a la relación de confianza, apoyo e inserción social de mujeres violentadas conjuntamente con la Unidad de Policía Pacificadora.

Descriptores: Enfermería; Salud de la Mujer; Violencia contra la Mujer; Mujeres Maltratadas; Género y Salud. 


\section{INTRODUÇÃO}

Historicamente, a violência contra as mulheres tem sido tolerada e naturalizada no cotidiano das interações em diversas sociedades. No Brasil, apenas no final do século XX, a violência vivenciada pela população feminina passou a ser agendada politicamente como violação aos direitos humanos. Mecanismos para coibir e prevenir atos de agressão e violência por parceiro íntimo e familiar contra mulheres foram criados, devido à mobilização e à conscientização produzidas pelos movimentos sociais, pelas organizações, convenções em nível internacional, com posterior repercussão nacional(1).

A violência é um fenômeno complexo que deve ser compreendido nas suas mais diferentes formas, considerando-se os atos agressivos contra a mulher. A Assembleia Geral das Nações Unidas, em 1993, aprovou a declaração sobre a eliminação de atos violentos contra a mulher, definindo a ação como qualquer ato de violência baseado no gênero que resulte, ou tenha probabilidade de resultar, em dano físico, sexual, psicológico ou sofrimento, incluindo a ameaça de praticar tais atos; incluem-se também coerção ou privação da liberdade, tanto na vida pública como privada(2).

No Brasil, as ações desenvolvidas nas décadas de 80 e 90 criaram condições necessárias para o surgimento da Lei 11.340/06 (Lei Maria da Penha) em 2006. Esta estabelece a violência contra a mulher como qualquer ação ou omissão baseada em gênero que lhe cause morte, lesão, sofrimento físico, sexual ou psicológico e dano moral ou patrimonial. A violência pode ocorrer na unidade doméstica, na família e em qualquer relação íntima de afeto, constituindo uma das formas de violação dos direitos humanos ${ }^{(3)}$.

A iniciativa atribuída à Lei Maria da Penha motivou programas e políticas de proteção à mulher vítima de violência. Esse salto deu-se principalmente pela melhor qualificação dos profissionais que atuam nas Delegacias Especializadas de Atendimento a Mulher (DEAMs), CasasAbrigo e Centros de Atendimento à Mulher, ou seja, todos os centros de referência para a violência de gênero. No entanto, ainda existem lacunas a preencher, pois o enfrentamento da violência pelas mulheres ainda carece de medidas que as protejam de forma efetiva e concreta ${ }^{(4)}$.

Para se compreender a denominação de violência de gênero, é preciso considerar o caráter social atribuído a homens e mulheres e reconhecer que as suas diferenças não são apenas no aspecto biológico, mas também no social. Os comportamentos femininos e masculinos são construções culturais e produtos da sociedade ${ }^{(5)}$.

Este tipo de violência pode ocorrer em espaços privados ou públicos, onde o autor pode ser o pai, o irmão, o parceiro íntimo ou ex-parceiro(3). Segundo a Organização das Nações Unidas, esta é uma das formas mais comuns de violência contra as mulheres que, em geral, estão emocionalmente envolvidas com os agressores, dependendo economicamente deles. A violência de gênero ocorre em todos os países, independentemente de grupo social, religioso ou cultural( ${ }^{(6)}$.

Pesquisa realizada em 2010 a partir dos registros de ocorrência de violência de gênero contra mulheres em Delegacias Especializadas de Atendimento à Mulher (DEAMs) da Região Metropolitana do Rio de Janeiro, no período de 2003 a 2008, caracterizou e analisou o perfil sociodemográfico da clientela assistida frente à situação da violência de gênero. Os resultados evidenciaram que a maioria dessas mulheres eram jovens, de baixo nível educacional, solteiras, de cor branca, em faixa etária reprodutiva; possuíam alguma ocupação remunerada e sofriam violência psicológica, principalmente por parte do parceiro íntimo. A própria residência era o local onde mais ocorria este tipo de violência ${ }^{(7)}$.

O Instituto de Segurança Pública do Estado do Rio de Janeiro publicou um estudo em 2012, chamado Dossiê Mulher e realizou um levantamento dos dados de registros de ocorrência (RO) das Delegacias de Polícia do Rio de Janeiro. Este dossiê teve por objetivo traçar um diagnóstico dos principais crimes relacionados à violência de gênero contra a mulher no ano de 2011. Neste ano, foram registrados 4.871 casos de estupro, 81.273 casos de ameaça, 84.709 casos de lesão corporal dolosa, 4.242 casos de tentativa de homicídio e 4.279 casos de homicídio doloso. Desses registros, os percentuais de mulheres vítimas foram, respectivamente, $82,6 \%, 66,8 \%$, $64,5 \%, 16,0 \%$ e $7,1 \%$. Ou seja, nos casos de estupro, ameaça e lesão corporal, a maioria das vítimas foi mulher ${ }^{(8)}$.

Mulheres, parceiros, incidências e resistências no campo da violência de gênero contra a mulher parecem ser alguns "nós" de uma rede de processos multidirecionais que, hoje, apresentam a violência como um problema público altamente complexo. Classificado mais recentemente como uma questão de segurança 
pública e justiça, alvo de medidas punitivas, este fenômeno vem sendo considerado também como um problema de saúde pública(9).

A violência de gênero contra a mulher afeta a integridade biopsicossocial deste sujeito(10), o que ressalta a necessidade de preparo dos profissionais de saúde e de segurança para lidar, de forma sensível e eficaz, com essa temática. O enfrentamento da violência não deve ser centralizado no tratamento de suas consequências, mas na prevenção primária, através de ações que permitem o desenvolvimento de mecanismos que possibilitam o empoderamento das mulheres para desconstruir a desigualdade estabelecida e reconstruir relações equitativas de gênero(11).

Neste sentido, a presença das Unidades de Polícia Pacificadora (UPPs) em comunidades pacificadas no município do Rio de Janeiro traz a participação do Estado em regiões anteriormente dominadas pelo tráfico de drogas, entre outros, e sugerem alternativas para encorajar mulheres a denunciarem seus agressores, uma vez que existe o fácil acesso às mulheres, aliado à sensação de proteção e segurança que este órgão possa transmitir(12).

Neste artigo são apresentados resultados de uma pesquisa que teve como objetivo investigar a violência de gênero contra a mulher a partir dos registros de uma Unidade de Polícia Pacificadora quanto às formas de violência, local de ocorrência, relação do agressor com a mulher e suas correlações.

Este, diferentemente de outros estudos, que são realizados em cenários de atenção à saúde da mulher $(2,9,13)$ ou em cenários relativos à segurança pública, como Delegacias Convencionais e Delegacias Especializadas de Atendimento à Mulher ${ }^{(7,11,14-15)}$, evidenciam uma lacuna no que diz respeito ao desenvolvimento de pesquisas com dados de Unidades de Polícia Pacificadora (UPP). Fato que confere relevância, considerando ser uma realidade até então oculta e de difícil acesso aos pesquisadores. Este estudo abre espaço para detecção de novos casos e, consequentemente, poderá subsidiar ações que instrumentalizem os profissionais de saúde no atendimento à mulher em situação de violência de gênero.

\section{MÉTODOS}

Estudo quantitativo, retrospectivo e transversal, realizado em uma Unidade de Polícia Pacificadora (UPP), localizada em uma comunidade pacificada da Zona Sul do município do Rio de Janeiro. A UPP exerce um patrulhamento efetivo, garantindo à população o acesso a serviços básicos para o livre exercício da cidadania. Esta Unidade obedece a nova política de segurança pública do Estado do Rio de Janeiro e foi uma das primeiras a serem criadas, possuindo um melhor domínio do território e apoio social da população ali residente.

No que concerne às mulheres em situação de violência de gênero que residem nessa comunidade, elas podem visualizar uma UPP como um órgão de defesa aos seus direitos, onde poderá denunciar o seu parceiro agressor. O papel das autoridades é o de amparar estas mulheres fragilizadas em sua integralidade, ajudando-as a resgatar o seu papel de cidadã por meio do enfrentamento diante da denúncia e outras providências.

Este estudo constitui-se da análise dos registros de mulheres que vivenciaram episódios de violência e recorreram a uma UPP. Segundo o Tenente responsável pela unidade, o trabalho nesses casos consiste em intervir no conflito entre as partes, com o objetivo de minimizar ou evitar os danos físicos, psicológicos e materiais. Posteriormente, realiza-se uma notificação nos Talões de Registro de Ocorrência (TROs). Os policiais encaminhamse para a moradia da solicitante e aplicam as medidas cabíveis aos agressores (o que pode incluir detenção) e sugerem à mulher acompanhá-la até a delegacia para que possa realizar o registro em Boletim de Ocorrência (BO), o que fará com que o agressor responda criminalmente por seus atos. De acordo com os policiais da UPP, muitas destas mulheres não vão à delegacia registrar o ocorrido, justificando que se dão por satisfeitas com a intervenção dos mesmos. Tal fato demonstra que a presença dos policiais transmite respeito, confiança e segurança familiar, como política de pacificação.

Os dados foram extraídos da fonte primária da UPP por meio dos TROs de janeiro de 2011 a março de 2012. Neste período foi obtido um total de 107 TROs que tratavam dos casos de violência de gênero contra a mulher. Porém, alguns registros não traziam informações suficientes, o que caracteriza alguns casos de subnotificações. Foi a partir do ano de 2011 que está UPP começou a se organizar de forma consistente com o propósito de atender aos casos de violência de gênero contra a mulher na comunidade. Desta forma, foi selecionada uma amostra final de 89 (100\%) registros executados de forma completa pelas autoridades 
responsáveis e que apresentavam informações suficientes para a realização do estudo. A coleta de dados foi realizada no período de dezembro de 2011 a março de 2012. Para a inclusão dos TROs na pesquisa os critérios foram: registros de mulheres maiores de idade (acima de 18 anos), que vivenciaram a violência de gênero e residiam nesta comunidade pacificada do Rio de Janeiro.

As variáveis utilizadas seguiram as informações contidas nos TROs, como tipo de violência de gênero contra a mulher; denúncia na Delegacia de Polícia; local de ocorrência da violência; agressor e relação do agressor com a vítima.

As informações obtidas foram transcritas para um instrumento elaborado pelos pesquisadores e, após a coleta dos dados, digitadas em planilha Excel 2010 e transferidas para o programa SPSS 17.0. Foi realizada a análise descritiva das variáveis, sob a forma de frequência absoluta e relativa. Para o cruzamento entre as variáveis, foi aplicado o teste estatístico qui-quadrado ao nível de significância de $95 \%$.

O estudo foi aprovado pelo Comitê de Ética em Pesquisa da Escola de Enfermagem Anna Nery e Hospital Escola São Francisco de Assis da Universidade Federal do Rio de Janeiro, sob o protocolo número 098/2011, atendendo às recomendações da Resolução 196/96 do Conselho Nacional de Saúde. Todos os dados coletados foram mantidos em sigilo.

\section{RESULTADOS}

A Tabela 1 apresenta os dados coletados nos Talões de Registro de Ocorrência (TROs) em uma UPP, localizada em uma comunidade pacificada da Zona Sul do município do Rio de Janeiro. Observa-se o predomínio de registros de violência física contra a mulher, seguida de violência psicológica e um menor percentual de registros relacionados à violência sexual.

Tabela 1: Dados dos Talões de Registros de Ocorrência de violência de gênero contra a mulher em uma Unidade de Polícia Pacificadora. Rio de Janeiro, RJ, Brasil, 2011/2012.

\begin{tabular}{|c|c|c|}
\hline Variáveis & $\mathbf{N}$ & $\%$ \\
\hline \multicolumn{3}{|l|}{ Tipos de violência contra a mulher } \\
\hline Física e Psicológica & 7 & 7,9 \\
\hline Física & 59 & 66,3 \\
\hline Psicológica & 21 & 23,6 \\
\hline Sexual & 2 & 2,2 \\
\hline \multicolumn{3}{|c|}{ Denúncia na Delegacia de Polícia ou Delegacia Especializada em Atendimento às Mulheres (DEAMs) } \\
\hline Não & 45 & 50,6 \\
\hline Sim & 44 & 49,4 \\
\hline \multicolumn{3}{|l|}{ Local de ocorrência da violência } \\
\hline Residência & 62 & 69,7 \\
\hline Fora de residência & 27 & 30,3 \\
\hline \multicolumn{3}{|l|}{ Agressor } \\
\hline Conhecido & 63 & 70,8 \\
\hline Desconhecido & 26 & 29,2 \\
\hline \multicolumn{3}{|l|}{ Relação do agressor com a mulher que vivenciou a violência } \\
\hline Parceiro íntimo atual & 48 & 53,9 \\
\hline Desconhecido & 26 & 29,2 \\
\hline Ex-parceiro íntimo & 7 & 7,9 \\
\hline Família & 8 & 9,0 \\
\hline Total & 89 & 100,0 \\
\hline
\end{tabular}

Fonte: Unidade de Polícia Pacificadora (UPP) da Zona Sul do Município do Rio de Janeiro.

Ao analisarmos esta primeira tabela, constata-se, pelos registros, que a maioria das mulheres não realizou a denúncia na Delegacia de Polícia ou DEAMs, fato este que impossibilita a aplicação da Lei Maria da Penha, já que a UPP funciona como mediadora de conflito, orientando as mulheres a realizar a denúncia em boletim de ocorrência na Delegacia de Polícia mais próxima. Vale destacar que, no caso da mulher decidir pela denúncia, os policiais da UPP a acompanham até a delegacia.
Quanto ao local de ocorrência da violência de gênero contra a mulher, os registros mostraram que a residência da vítima representa o espaço com maior prevalência do evento, sendo os agressores conhecidos e, em sua maioria, esses agressores correspondem ao próprio parceiro íntimo atual.

A Tabela 2 mostra o tipo de violência de gênero nos níveis de cada variável e sua associação com as variáveis 
em estudo em mulheres que vivenciaram agressões pelos

parceiros íntimos.

Tabela 2: Número de mulheres (n) em cada nível da variável explanatória, frequência (f), percentagem (\%) do tipo de violência e o valor de p do teste (qui-quadrado). Unidade de Polícia Pacificadora. Rio de Janeiro, RJ, Brasil, 2011/2012.

\begin{tabular}{|c|c|c|c|c|c|c|}
\hline \multirow{2}{*}{ Variáveis } & \multirow{2}{*}{$\mathbf{N}$} & \multicolumn{4}{|c|}{ Tipo da violência f (\%) } & \multirow{2}{*}{ p-valor } \\
\hline & & Física e Psicológica & Física & Psicológica & Sexual & \\
\hline \multicolumn{7}{|l|}{ Denúncia } \\
\hline Não & 45 & $4(57,1 \%)$ & $24(40,7 \%)$ & $15(71,4 \%)$ & $2(100,0 \%)$ & 0,030 \\
\hline Sim & 44 & $3(42,9 \%)$ & $35(59,3 \%)$ & $6(28,6 \%)$ & $0(0,0 \%)$ & \\
\hline \multicolumn{7}{|l|}{ Agressor } \\
\hline Conhecido & 63 & $6(85,7 \%)$ & $42(71,2 \%)$ & $14(66,7 \%)$ & $1(50,0 \%)$ & 0,701 \\
\hline Desconhecido & 26 & $1(14,3 \%)$ & $17(28,8 \%)$ & $7(33,3 \%)$ & $1(50,0 \%)$ & \\
\hline \multicolumn{7}{|l|}{ Local ocorrência } \\
\hline Residência & 62 & $5(71,4 \%)$ & $40(67,8 \%)$ & $15(71,4 \%)$ & $2(100,0 \%)$ & 0,663 \\
\hline $\begin{array}{c}\text { Fora da residência } \\
\text { Relação com agressor }\end{array}$ & 27 & $2(28,6 \%)$ & $19(32,2 \%)$ & $6(28,6 \%)$ & $0(0,0 \%)$ & \\
\hline Parceiro atual & 48 & $4(57,1 \%)$ & $29(49,2 \%)$ & $14(66,7 \%)$ & $1(50,0 \%)$ & \\
\hline Desconhecido & 26 & $1(14,3 \%)$ & $17(28,8 \%)$ & $7(33,3 \%)$ & $1(50,0 \%)$ & - \\
\hline Ex-parceiro íntimo & 7 & $2(28,6 \%)$ & $5(8,5 \%)$ & $0(0,0 \%)$ & $0(0,0 \%)$ & \\
\hline Família & 8 & $0(0,0 \%)$ & $8(13,6 \%)$ & $0(0,0 \%)$ & $0(0,0 \%)$ & \\
\hline
\end{tabular}

Fonte: Unidade de Polícia Pacificadora (UPP) da Zona Sul do Município do Rio de Janeiro.

Nota-se que a maioria das mulheres vítimas de violência física e psicológica, ou pertencentes ao grupo que vivenciou a violência psicológica ou sexual, não denunciou o agressor; entretanto, no grupo de mulheres vítimas da violência do tipo física, houve uma maior proporção de denúncias. Quanto à relação entre o tipo de violência e as variáveis agressor, local de ocorrência e relação com o agressor, não houve significância estatística.

A Tabela 3 apresenta as correlações entre as diferentes variáveis em relação ao agressor no que se refere à realização da denúncia, local de ocorrência e relação da mulher com o agressor.

Tabela 3: Número de mulheres ( $n$ ) em cada nível da variável explanatória, frequência (f), percentagem (\%) da realização da denúncia e o valor de p do teste (qui-quadrado). Unidade de Polícia Pacificadora. Rio de Janeiro, RJ, Brasil, 2011/2012.

\begin{tabular}{|c|c|c|c|c|}
\hline \multirow{2}{*}{ Variáveis } & \multirow{2}{*}{$\mathbf{N}$} & \multicolumn{2}{|c|}{ Realização da Denúncia f (\%) } & \multirow{2}{*}{ p valor } \\
\hline & & Não & Sim & \\
\hline \multicolumn{5}{|l|}{ Agressor } \\
\hline Conhecido & 63 & $36(80,0 \%)$ & $27(61,4 \%)$ & 0,053 \\
\hline Desconhecido & 26 & $9(20,0 \%)$ & $17(38,6 \%)$ & \\
\hline \multicolumn{5}{|l|}{ Local ocorrência } \\
\hline Residência & 62 & $36(80,0 \%)$ & $26(59,1 \%)$ & 0,032 \\
\hline Fora da residência & 27 & $9(20,0 \%)$ & $18(40,9 \%)$ & \\
\hline \multicolumn{5}{|l|}{ Relação com agressor } \\
\hline Parceiro íntimo atual & 48 & $26(57,8 \%)$ & $22(50,0 \%)$ & \\
\hline Desconhecido & 26 & $9(20,0 \%)$ & $17(38,6 \%)$ & 0,059 \\
\hline Ex-parceiro íntimo & 7 & $3(6,7 \%)$ & $4(9,1 \%)$ & \\
\hline Família & 8 & $7(15,6 \%)$ & $1(2,3 \%)$ & \\
\hline
\end{tabular}

Fonte: Unidade de Polícia Pacificadora (UPP) da Zona Sul do Município do Rio de Janeiro.

Demonstra-se, na tabela acima, que não houve associação significativa entre a realização da denúncia e as variáveis agressor e relação com o agressor. Todavia, ao correlacionar a realização da denúncia com a variável local de ocorrência, constata-se relação entre as variáveis. Evidencia-se no grupo de mulheres que não denunciaram o agressor, que a maioria dos casos de violência de gênero ocorreu no âmbito de residência da vítima; já no grupo que denunciou o agressor, o percentual de ocorrência deste tipo de violência em domicílio é menor.

A Tabela 4 mostra a relação entre as variáveis local de ocorrência da violência e relação da mulher com o agressor. 
Tabela 4: Número de mulheres ( $\mathrm{n}$ ) em cada nível da variável explanatória, frequência (f), percentagem (\%) do local de ocorrência e o valor de p do teste (qui-quadrado). Unidade de Polícia Pacificadora. Rio de Janeiro, RJ, Brasil, $2011 / 2012$.

\begin{tabular}{|c|c|c|c|c|}
\hline \multirow{3}{*}{ Variáveis } & \multirow{3}{*}{$\mathbf{N}$} & \multicolumn{2}{|c|}{ Local da ocorrência } & \multirow{3}{*}{ p-valor } \\
\hline & & Residência & Fora da Residência & \\
\hline & & n (\%) & n (\%) & \\
\hline \multicolumn{5}{|l|}{ Agressor } \\
\hline Conhecido & 63 & $56(90,3 \%)$ & $7(25,9 \%)$ & 0,000 \\
\hline Desconhecido & 26 & $6(9,7 \%)$ & $20(74,1 \%)$ & \\
\hline \multicolumn{5}{|l|}{ Relação com agressor } \\
\hline Parceiro íntimo atual & 48 & $43(69,4 \%)$ & $5(18,5 \%)$ & \\
\hline Desconhecido & 26 & $6(9,7 \%)$ & $20(74,1 \%)$ & 0,000 \\
\hline Ex-parceiro íntimo & 7 & $6(9,7 \%)$ & $1(3,7 \%)$ & \\
\hline Família & 8 & $7(11,3 \%)$ & $1(3,7 \%)$ & \\
\hline
\end{tabular}

Fonte: Unidade de Polícia Pacificadora (UPP) da Zona Sul do Município do Rio de Janeiro.

Verifica-se na tabela acima, ao cruzar as variáveis local de ocorrência da violência e agressor, que houve uma relação extremamente significante. Nota-se que a violência de gênero que ocorre na residência da vítima, na maioria das vezes, o agressor é conhecido; entretanto, quando a violência contra a mulher acontece fora da residência, em grande parte é praticada por um desconhecido. No que tange à relação entre o local de ocorrência e a relação com o agressor, verifica-se significância estatística. Mulheres que sofreram violência na residência, na maioria das vezes, os agressores são os parceiros íntimos atuais; já quando a violência é vivenciada fora da residência, há uma maior proporção de agressores desconhecidos.

\section{DISCUSSÃO}

O resultado do estudo evidenciou que os atos de violência de gênero cometidos contra as mulheres ocorreram dentro do domicílio e os agressores são conhecidos, sendo na maioria os parceiros íntimos. Este dado é corroborado pela Organização das Nações Unidas $^{(6)}$, quando aponta que as estatísticas disponíveis a partir dos registros nas delegacias especializadas de crimes contra a mulher, demonstram que $70 \%$ dos fatos ocorrem dentro de casa e que o agressor é um membro da família.

A literatura ${ }^{(6,14,16)}$ aponta que o ambiente doméstico é o local preferido pelo agressor, por ser resguardado da opinião e interferência de terceiros. Este fato ocorre pela indiferença da sociedade frente à violência de gênero que acontece dentro do lar, tornando-o espaço para agressões. Essa atitude que naturaliza a violência na sociedade é fruto do patriarcalismo, onde a desigualdade de gênero é o resultado de assimetria de poder que se traduz em relações de força e dominação.
Na dominação entre os sexos, sobretudo na cultura latino-americana, o sexo masculino exerce a dominação física e psíquica, com legitimidade social. Essa dominação, a princípio imposta pela maior força física, é ampliada para as dimensões psicológicas e tem o reconhecimento cultural manifesto no respeito ao espaço privado das relações conjugais que se expressam até nos provérbios populares, como o que afirma: "Em vida de marido e mulher, ninguém deve meter a colher". Contudo, essa dominação inferioriza as mulheres desqualificando o "outro" da relação como algo "natural" e insuperavelmente inferior, porque biologicamente diferente ${ }^{(15)}$.

Os resultados deste estudo expressam o predomínio da violência física sobre a violência psicológica e sexual. Estes dados são corroborados pela Organização das Nações Unidas ${ }^{(6)}$, quando apontam que aproximadamente 534.000 mulheres no mundo foram expostas à violência física e aproximadamente $30 \%$ das brasileiras foram agredidas fisicamente, pelo menos uma vez na vida, pelos parceiros íntimos.

Pesquisa realizada no Brasil(17) também expressa outros dados por meio de opinião pública. Nesta, investigou-se 2.365 mulheres brasileiras, com mais de 15 anos de idade. Este estudo revelou que, a cada 24 segundos, uma mulher é agredida. $O$ atual parceiro ou exparceiro íntimo foi responsável por mais de $80 \%$ dos casos, e $16 \%$ das mulheres relataram que já levaram tapas, empurrões ou sacudidas, caracterizando a violência física.

Em outro estudo(18), com o propósito de compreender o sentimento das mulheres que vivenciaram este tipo de violência de maridos, parceiros íntimos ou namorados, percebeu-se que, além dos danos físicos, foram reveladas também, implicações emocionais 
que as levam a avaliar seus sentimentos em relação ao relacionamento. Elas revelaram que houve a quebra do romantismo, o que se reflete também na qualidade da vida sexual.

Embora os dados apontem que a violência física tenha sido mais expressiva pelas mulheres neste estudo, por meio de ocorrências tipificadas criminalmente por lesões corporais, sabemos que, muitas vezes, este tipo de agressão é seguida pela violência psicológica, caracterizada pelas injúrias, ameaças e difamações ${ }^{(16)}$. Os dados obtidos evidenciam que o quantitativo de queixas registradas como violência sexual foi pequena; entre esses, podem haver situações de estupros conjugais. Muitas mulheres não reconhecem este ato como uma agressão, pensando que seus parceiros podem ter relações sexuais com elas, mesmo sem 0 seu consentimento.

Em alguns países da América Latina, acontece a naturalização da violência de gênero contra a mulher, pois estas compactuam com o comportamento autoritário dos homens, naturalizando o uso da força, o que pode ser traduzido como a legitimação do direito do homem sobre a mulher ${ }^{(16)}$.

Os casos de violência sexual merecem atenção especial, considerando a gravidade do ato e as consequências prejudiciais para a saúde, principalmente o risco de exposição à Doenças Sexualmente Transmissíveis (DSTs). Este tipo de violência afeta a multidimensionalidade das vítimas, ocasionando problemas de saúde física, reprodutiva e mental, como lesões corporais, fobias, pânico, síndrome do estresse pós-traumático, além dos problemas familiares e sociais, como abandono dos estudos, perda de empregos, separações conjugais e abandono de casa(19). Em muitas situações, mulheres que vivem com parceiros violentos não têm escolha no uso de contraceptivos, o que favorece uma gravidez indesejada e abortos espontâneos.

Nesta perspectiva, pesquisa realizada em São Paulo reforça este pensamento quando revela que, atualmente no Brasil, apenas as mulheres que sofrem violência sexual perpetrada por estranhos são contempladas com práticas preventivas, como a quimioprofilaxia do HIV, em serviços de referência específicos para essa forma de violência(20). Portanto, há a necessidade de um olhar atentivo dos profissionais de saúde e de segurança inseridos nos serviços que atendem às mulheres em situação de violência sexual, inclusive a praticada pelo parceiro íntimo que deve fazer parte de cuidados preventivos.

Ao analisar os dados, evidencia-se que foi muito pequena a diferença quantitativa entre aquelas mulheres que formalizaram a denúncia contra o agressor em Boletim de Ocorrência (BO) na Delegacia de Polícia, contra aquelas que não o fizeram. O registro do $\mathrm{BO}$ pode dar origem a um Inquérito Policial ou Termo Circunstanciado. O Inquérito Policial é um procedimento instaurado com a finalidade de reunir elementos necessários para esclarecer a prática de uma infração penal em crimes de maior potencial ofensivo como, por exemplo, no caso do estupro e lesões corporais graves. Por outro lado, o Termo Circunstanciado consiste no registro de ocorrência de violência, porém de maneira mais completa que o BO, empregado em crimes de menor potencial ofensivo ${ }^{(21)}$.

De acordo com os resultados, nota-se que a maioria dos casos de violência de gênero contra a mulher aconteceu dentro da própria residência, sendo o agressor o parceiro íntimo. Estudos ${ }^{(1-2,7)}$ corroboram com esses dados e acrescentam que em decorrência de fatores como a dependência econômica e afetiva das mulheres, a existência de filhos menores, o fato de não exercerem atividade remunerada, entre outros, as mulheres não denunciam seus agressores. Assim, elas permanecem expostas aos comportamentos agressivos do parceiro, contrariando as expectativas da dinâmica familiar idealizada pela sociedade. O lar, espaço que a família acredita ser seguro, muitas vezes pode conter agressões. Ainda há escassez de dados que revelem os índices de violência de gênero contra a mulher, que inclui como agressores, além de familiares, outros membros do grupo que convivem no espaço doméstico(22).

Este estudo evidenciou ainda que a maioria das mulheres que vivenciou violência física registrou o BO na delegacia, enquanto a maioria daquelas que vivenciaram violência psicológica e sexual não registraram. As agressões físicas são mais evidentes de serem observadas, através das marcas deixadas no corpo. Quando um relacionamento chega ao ponto dessa agressão, significa que as discussões já vêm ocorrendo sobremaneira, até chegar ao ápice, caracterizado por um tapa ou um soco.

Os resultados desse estudo, de uma forma geral, são congruentes com outras pesquisas ${ }^{(8,18)}$. Estas evidenciam 
também que a maioria das mulheres que vivenciaram a violência física registrou o BO na delegacia.

Entretanto, o mesmo não ocorreu quando as mulheres vivenciaram a violência psicológica e sexual, o que expressa, por inferência, não reconhecerem estes fatos como um problema que deve ser denunciado aos órgãos de segurança. Os resultados encontrados são corroborados por outros estudos ${ }^{(19-20)}$ com enfoque maior na violência sexual, onde afirmam que esta forma de agressão é difícil de ser estimada face às questões de gênero e pode estar associada às outras formas de violência. Por outro lado, o contato com a UPP possibilitou ações de promoção de uma coletivização de práticas que aproximaram os problemas vivenciados pelas mulheres, contribuindo para um aprofundamento das experiências de violência, proporcionando possíveis mudanças e enfrentamentos desta situação.

Apesar das proteções legais pré-determinadas pela justiça, a mulher ainda se encontra em situação de vulnerabilidade social. Portanto, aquelas que resolvem denunciar as agressões, parecem viver uma segunda violência posteriormente, ou seja, aquela resultante do ato violento em si e aquela da invasão de sua privacidade pela exposição dos atos.

As consequências da violência de gênero contra a mulher, independente da forma de manifestação tem, na vergonha do ato vivenciado, uma invasão de sua privacidade, a negação de sua liberdade e integridade e a culpabilidade por não terem sido capazes de resistir suficientemente. Aos olhos dos outros, o fato de terem sofrido violência se reveste de significados estruturados por um padrão de relações sexuais hierárquicas, no qual a mulher se apresenta por vezes merecedora desta violência(23).

Outra correlação encontrada foi que a maioria das mulheres que não registrou a denúncia em $\mathrm{BO}$ sofreu a violência dentro de casa. Não é difícil perceber como muitas delas sentem-se envergonhadas ao procurar uma instituição de segurança a fim de obter apoio diante de um caso de violência vivenciada dentro de sua própria casa e perpetrada pelo seu parceiro íntimo. Por outro lado, existem aquelas que se encorajam de alguma forma com a tomada de decisão e denunciam seus parceiros, mesmo sendo uma minoria.

As razões que levam as mulheres a realizar esta denúncia ocorrem pelo receio de novas agressões ou ameaças, e por terem que fazer algo para "ferrar" o parceiro ou "botar pra quebrar", para "procurar meus direitos", "tomar atitude" ou "mostrar para ele que eu não sou igual àquelas outras". A busca por este recurso devese ao efeito produzido no contexto familiar da vítima. A intervenção policial possibilita a autoproteção e repreensão da conduta do parceiro(24).

O profissional de segurança pública ou de saúde, ao atender uma mulher nessas condições, deverá compreender a passagem do natural para o cultural, pois se a violência de gênero for tratada como natural por certos indivíduos e, em particular pelas mulheres, podese estar sendo conivente com a situação e cúmplice da violência(13).

Um profissional que atende a esta mulher no serviço de saúde não deverá subjugar ou duvidar da gravidade da violência de gênero vivenciada por ela; este ato gera consequências graves a sua saúde mental e integridade das suas relações sociais. A violência psicológica gera transtornos para a saúde e demandam intervenções de uma equipe multidisciplinar, onde exista diálogo entre os setores de enfermagem e psicologia. A atuação dos serviços de saúde é necessária nos casos de violência e na baixa autoestima da mulher que convive com as agressões $^{(25)}$.

\section{CONCLUSÃO}

As variáveis levantadas na UPP possibilitaram identificar que os índices de violência psicológica e sexual foram pequenos, pois aquelas que vivenciaram esses tipos de violência não denunciaram nas delegacias. Por outro lado, a maioria daquelas mulheres que passaram pela violência física no domicílio denunciou o agressor e o percentual desta ocorrência foi maior. Aquelas mulheres violentadas em sua residência, a maioria sofreu agressões pelas mãos do próprio parceiro íntimo atual.

A contribuição deste estudo, conforme mencionado anteriormente, refere-se aos espaços constituídos como possibilidade de oferecer atendimento às mulheres em situação de violência na busca de soluções muito mais coletivas do que individuais. A implementação das UPPs nessas áreas teve por objetivo resgatar a cidadania de uma população que anteriormente era subjugada por criminosos. Atualmente, com estes resultados, pode-se verificar a real situação em que vivem as mulheres que sofrem com a violência de gênero, se pensar estratégias que resguardem a integridade dessas mulheres, e intervir 
no enfrentamento da violência e das necessidades que ela produz.

Ao se perceber esta realidade por outro ângulo, as mulheres que vivenciaram a violência de gênero e que mais denunciaram os seus agressores junto das delegacias são aquelas que sofreram a violência física, fora da residência, e por pessoa desconhecida. Na comunidade onde vivem essas mulheres, a violência ainda está muito presente como uma forma de dominação daqueles que tentam impor um domínio paralelo, mesmo com a presença das forças de pacificação. Os registros indicam que as mulheres residentes nesta comunidade precisam contar com o apoio da UPP para intervir e mediar conflitos sociais e familiares.

O fato da pesquisa ter sido realizada com os registros de mulheres em situação de violência de gênero atendidas em uma Unidade de Polícia Pacificadora é uma limitação do estudo, considerando a magnitude desta problemática na sociedade, mas abre possibilidades para o vínculo de confiança e para estabelecer um trabalho conjunto entre a UPP e os profissionais de saúde. Justifica-se porque ainda não existem estudos realizados em Unidades de Polícia Pacificadora. Estas unidades prestam o serviço de segurança nas comunidades, onde também atuam profissionais da saúde.

Sugere-se a ampliação de pesquisas nesta ou em outras comunidades pacificadas do Rio de Janeiro, com o propósito de investigar diretamente essas mulheres que vivenciaram a violência de gênero, buscando as consequências dos atos de agressão a sua saúde física e psicológica, bem como os motivos que as levaram a denunciar os seus parceiros íntimos.

Neste contexto, analisar a violência de gênero contra a mulher a partir dos registros de uma Unidade de Polícia Pacificadora é reconhecer este ato como uma violação dos direitos humanos. Um ato de violência contraria os princípios de autonomia, cerceando o direito a sua integridade corporal. A mulher violentada necessita de uma atenção especial dos serviços de saúde no que se refere ao apoio e a sua inserção social. É imprescindível que ela seja não só acolhida, mas encaminhada para uma rede interinstitucional, com vistas ao acompanhamento psicológico.

6. United Nations. The World's Women 2010. Trends and Statistics [Internet]. United Nations: New York; 2010 [acesso em: 30 set 2013]. Disponível em:

http://unstats.un.org/unsd/demographic/products/Worldswom en/WW2010pub.htm.

7. Moura MAV, Menezes JP, Netto LA, Silva GF. Perfil sóciodemográfico de mulheres que sofreram com a violência de gênero no Rio de Janeiro: subsídios para a enfermagem. Revista de Pesquisa: Cuidado é Fundamental Online [Internet]. 2010 [acesso em: 30 set 2013];2 Supl.:418-22. Disponível em: http://www.seer.unirio.br/index.php/cuidadofundamental/articl e/viewArticle/963.

8. Instituto de Segurança Pública. Dossiê Mulher 2012. 7a ed.

Rio de Janeiro: Secretaria de Segurança Pública; 2012.

9. Granja E, Medrado B. Homens, violência de gênero e atenção integral em saúde. Psicol. Soc. [Internet]. 2009 [acesso em: 30 set 2013];21(1):25-34. Disponível em:

http://dx.doi.org/10.1590/S0102-71822009000100004.

10. Loxton D, Schofield M, Hussain R, Mishra G. History of Domestic Violence and Physical Health in Midlife. Violence Against Women [Internet]. 2006 [acesso em: 30 set 2013];12(8): 715-31. Disponível em: http://dx.doi.org/10.1177/1077801206291483.

11. Guedes RN, Silva ATMC, Fonseca RMGS. A violência de gênero e o processo saúde-doença das mulheres. Esc. Anna Nery [Internet]. 2009 [acesso em: 30 set 2013];13(3):625-31. Disponível em: http://dx.doi.org/10.1590/S141481452009000300024.

12. Silva LAM. Afinal, qual é a das UPPs? [Internet]. Rio de Janeiro: Observatório das Metrópoles; 2010 [acesso em: 30 set 2013]. Disponível em:

http://www.observatoriodasmetropoles.ufrj.br/artigo machado UPPs.pdf. 
13. Bonfim EG, Lopes MJM, Peretto M. Os registros profissionais do atendimento pré-natal e a (in)visibilidade da violência doméstica contra a mulher. Esc. Anna Nery [Internet]. 2010 [acesso em: 30 set 2013];14(1):97-104. Disponível em: http://dx.doi.org/10.1590/S1414-81452010000100015. 14. Leôncio KL, Baldo $P L$, João VM, Biffi RG. O perfil de mulheres vitimizadas e de seus agressores. Rev. enferm. UERJ [Internet]. 2008 [acesso em: 30 set 2013];16(3):307-12. Disponivel em: http://www.facenf.uerj.br/v16n3/v16n3a02.pdf. 15. Guedes RN, Silva ATMC, Coelho EAC. Violência conjugal: problematizando a opressão das mulheres vitimizadas sob olhar de gênero . Rev. Eletr. Enf. [Internet]. 2007 [acesso em: 30 set 2013];9(2):362-78. Disponível em: http://www.fen.ufg.br/revista/v9/n2/v9n2a06.htm. 16. Organização Mundial da Saúde. Informe Mundial sobre Violência e Saúde 2002. Genebra: OMS; 2002.

17. Fundação Perseu Abramo. Violência doméstica. In: Mulheres brasileiras e gênero nos espaços público e privado [Internet]. São Paulo: Fundação Perseu Abramo; 2010 [acesso em: 30 set 2013]. Disponivel em:

http://csbh.fpabramo.org.br/galeria/violencia-domestica. 18. Cortez MB, Souza L. Mulheres (in)subordinadas: o empoderamento feminino e suas repercussões nas ocorrências de violência conjugal. Psic.: Teor. e Pesq. [Internet]. 2008 [acesso em: 30 set 2013];24(2):171-80. Disponível em: http://dx.doi.org/10.1590/S0102-37722008000200006. 19. Labronici LM, Fegadoli D, Correa MEC. Significado da violência sexual na manifestação da corporeidade: um estudo fenomenológico. Rev Esc Enferm USP [Internet]. 2010 [acesso em: 30 set 2013];44(2):401-6. Disponivel em: http://dx.doi.org/10.1590/S0080-62342010000200023. 20. Barros C, Schraiber LB, França-Junior I. Association between intimate partner violence against women and HIV infection. Rev Saude Publica [Internet]. 2011 [acesso em: 30 set 2013];45(2):365-72. Disponível em: http://dx.doi.org/10.1590/S0034-89102011005000008. 21. Ferraz MIR, Labronici LM. Perfil da violência doméstica contra mulher em Guarapuava, Paraná. Cogitare Enferm [Internet]. 2009 [acesso em: 30 set 2013];14(2):261-8. Disponível em:

http://ojs.c3sl.ufpr.br/ojs/index.php/cogitare/article/view/1561 2.

22. Sagim MB, Biasoli-Alves ZM, Delfino V, Vanturini FP. Violência doméstica: a percepção que as vítimas têm de seu parceiro, do relacionamento mantido e das causas da violência. Cogitare Enferm [Internet]. 2007 [acesso em: 30 set 2013];12(1):30-6. Disponível em: http://ojs.c3sl.ufpr.br/ojs/index.php/cogitare/article/view/8260. 23. Santi LN, Nakano AMS, Lettiere A. Percepção de mulheres em situação de violência sobre o suporte e apoio recebido em seu contexto social. Texto Contexto Enferm [Internet]. 2010 [acesso em: 30 set 2013];19(3):417-24. Disponível em: http://dx.doi.org/10.1590/S0104-07072010000300002. 24. Brandão ER. Renunciantes de direitos? A problemática do enfrentamento público da violência contra a mulher: o caso da delegacia da mulher. Physis [Internet]. 2006 [acesso em: 30 set 2013];16(2):207-31. Disponível em:

http://dx.doi.org/10.1590/S0103-73312006000200005. 25. Porto M. Violência contra a mulher e atendimento psicológico: o que pensam os/as gestores/as municipais do SUS. Psicol. cienc. prof. [Internet]. 2006 [acesso em: 30 set 2013];26(3):426-39. Disponível em: http://dx.doi.org/10.1590/S1414-98932006000300007.

Artigo recebido em 24/09/2012.

Aprovado para publicação em 10/06/2013.

Artigo publicado em 30/09/2013. 